\title{
Editorial: escrever, submeter e publicar na Rebep, a nossa revista indexada
}

Em 2009 assumimos, com alegria e entusiasmo, a editoria da Revista Brasileira de Estudos de População - Rebep. Temos a honrosa e árdua missão de continuar e ampliar o trabalho intenso e bem-sucedido dos editores que nos antecederam, que marcaram sua gestão com brilho.

Contamos com a colaboração competente do Comitê Editorial composto por Ana Sílvia Volpi Scott, Guaraci Adeodato Alves de Souza, Luiz Antônio Pinto de Oliveira, Márcia Caldas de Castro, Morvan de Melo Moreira, Neeru Gupta, Roberto Nascimento Rodrigues e Rosana Baeninger, além da participação da assistente editorial Maria de Fátima Moreira Martins, para trabalharmos juntos, a fim de que a Rebep possa continuar a orgulhar seus associados como veículo de divulgação científica de destaque.

Neste passo, ressaltamos que a Rebep recebeu avaliação elevada junto à Capes, o que premia o trabalho dos editores anteriores e aumenta a responsabilidade e o desafio da atual editoria. Isso mostra que estamos em um momento bom e que novos horizontes se abrem para a Rebep. Ora, se sabemos que os periódicos são os principais meios responsáveis pela disseminação rápida e confiável da informação cientifica, devemos, também, observar que esta propagação se faz em duas direções: a da comunicação do conhecimento para o leitor e a da comunicação entre os pares da comunidade científica.

A primeira direção aponta para a visibilidade do periódico, para o universo de leitores atingido ou com potencialidade de atingir. É com aplausos que destacamos a iniciativa das gestões das editorias anteriores ao integrar a Rebep na rede SciELO. Como bem ressaltou nosso colega abepiano e ex-editor da revista, Carlos Eugênio de Carvalho Ferreira, trata-se, sem dúvida, de uma "importante conquista, que vem possibilitar maior disseminação e conhecimento, tanto no âmbito nacional como no internacional, dos artigos publicados na Rebep". Esta é uma realidade que não pode ser ignorada. A consulta em periódicos eletrônicos é preferencial na área científica, seja pelo pesquisador em busca de informação, seja por aquele que procura publicação. Os motivos que contribuem para isso são muitos, quase todos relacionados à agilidade inerente ao processo de publicação eletrônica (especialmente via web).

Neste contexto, a Rebep disponibiliza, por intermédio do SciELO, de forma gratuita e com texto completo do conteúdo dos fascículos, a versão eletrônica de sua série de publicações, a partir de 2005. Por isso, a versão eletrônica da revista foi incluída no Portal de Periódicos da Capes. Esta iniciativa propicia maior visibilidade tanto à publicação como aos autores que nela publicam, razão pela qual esperamos aumentar o número de submissões. Manter essa integração e explorar os meios colocados à disposição pela rede SciELO é um de nossos desafios.

A segunda direção indica a credibilidade do periódico, ou seja, pode-se crer na divulgação da informação científica originada das atividades de pesquisa e, a partir daí, surge o adensamento das redes de relações entre os pesquisadores, funcionando a divulgação científica como uma correspondência, cartas trocadas entre pesquisadores, como remonta a origem dos periódicos. Contudo, no mundo moderno, essas conexões ocorrem sem que haja destinatário específico. Aqui, vemos uma possibilidade de ampliar a ainda pequena divulgação da Rebep fora do círculo de associados da Associação Brasileira de Estudos Populacionais. Isto porque, embora a expectativa seja a de que a revista receba um número muito grande de submissões, a realidade ainda não é esta. Tudo isto, em meio ao fato de que nós, pesquisadores, estamos 
premidos por uma demanda crescente por publicações e diante da consideração do ato de publicar artigos como prova definitiva de efetiva atividade em pesquisa científica. Então, se a Rebep é um periódico que está bem estabelecido e consolidado, precisamos trabalhar para ampliar a divulgação de nossa revista, para que possamos aumentar a rede de pesquisadores interessados em nela publicar.

No sentido de ampliar a visibilidade dos nossos trabalhos, estamos envidando esforços para fomentar o recebimento de submissões na língua inglesa. Além disso, solicitamos a todos os associados a colaboração na divulgação da Rebep, que tem como missão estimular e difundir a produção brasileira no campo da demografia e dos Estudos de População e garantir o diálogo entre este campo e áreas afins.

Porque a Rebep é composta de artigos inéditos no campo de estudos populacionais, alguns dos quais decorrem de dissertações de mestrado ou teses de doutorado, gostaríamos de ressaltar, aqui, a importância da divulgação dos diversos trabalhos desenvolvidos em uma tese ou dissertação na forma de artigos científicos. Por outro lado, reconhecemos que a necessidade de adaptação de teses e dissertações para publicação em revistas científicas faz com que artigos destinados a periódicos fiquem, muitas vezes, à espera de que se tenha tempo suficiente para que possam ser finalizados. É importante, então, que nos detenhamos um pouco nisso.

Como os periódicos são os principais responsáveis pela disseminação ágil e eficiente da informação cientifica, os autores das teses e dissertações que não se sentem estimulados a divulgar seu trabalho nestes veículos deixam escapar uma extraordinária oportunidade de aprendizagem e enriquecimento. Em parte, essa oportunidade é potencializada pelo diálogo ou debate com a posição emitida por pareceristas, sempre com o intuito de aprimorar a qualidade, o conteúdo, a forma e o rigor científico dos trabalhos submetidos para publicação.

É com base nesse conjunto de perspectivas, que apontam, todas, na direção de buscar uma maior difusão do conhecimento científico, com competência, qualidade e espaço para a pluralidade de manifestações e debate, que convidamos a todos a submeterem seus artigos a esta revista. Ressaltamos que, como se trata de uma publicação indexada na rede SciELO, de acesso público gratuito, os leitores podem sempre citar a Rebep em seus artigos, mesmo aqueles enviados para outros periódicos, pois isto aumenta nossa visibilidade e melhora nossos índices de classificação. Com certeza, não pouparemos esforços para o aprimoramento da revista, procurando ampliar o número de autores, oriundos das mais diversas instituições de ensino e pesquisa brasileiras e internacionais, propiciando visibilidade ao que se tem produzido no campo dos estudos populacionais.

Essa diversidade pode ser identificada neste primeiro número da Rebep em 2009, que marca o início do nosso trabalho na editoria da revista. O conteúdo dos doze textos publicados, sendo um artigo de revisão, oito artigos de pesquisa, um ponto de vista, duas notas de pesquisa e uma resenha, pode ser agrupado em seis conjuntos temáticos: uso dos Sistemas de Informação; trabalhos de cunho metodológico; demografia dos povos indígenas; mobilidade e migração; formação de família; e mortalidade.

No que se refere ao uso dos Sistemas de Informação, o objetivo da pesquisa apresentada por Drumond e colaboradoras foi descrever e avaliar a evolução da produção científica no Brasil, com base em dados secundários de três fontes de dados: SIM, Sinasc e SIH. Os resultados indicam crescimento muito expressivo da produção brasileira, especialmente a partir do final dos anos 1990.

Quanto aos trabalhos de cunho metodológico, Miranda-Ribeiro e colaboradores compararam dois métodos para a reconstrução das histórias de nascimento, utilizando, de forma criativa e instigante, ferramentas de relacionamento de registros. Caetano e Machado, por seu turno, ressaltam aspectos referentes ao método Grade of Membership, cada vez mais utilizado em estudos populacionais, com ênfase na busca de um modelo estatisticamente convergente para uma solução ótima. Finalmente, Jardim e colaboradoras detêm-se em algo extremamente importante, não apenas em inquéritos de saúde, mas em todo tipo de levantamento: formas 
de avaliar a reprodutibilidade da resposta do informante primário pelo informante secundário (ou substituto).

O grupo temático demografia dos povos indígenas é representado pelos artigos de Machado e colaboradores; Pena e colaboradores; Wong e colaboradoras; e Fígoli e Fazito, revelando a gama de estudos de qualidade que podem ser elaborados para esta população específica. Verifica-se que os estudos incluem desde um foco mais exploratório, no perfil demográfico, passando por uma contextualização política e socioeconômica de aspectos demográficos e por considerações acerca do comportamento reprodutivo, até chegar a uma análise de migração com base na atuação de redes sociais. Além disso, os estudos também se caracterizam pela diversidade de universos de investigação.

Em mobilidade e migração, o estudo de Batista e Cacciamali aborda, em âmbito nacional, as diferenças de salário segundo sexo e condição de migração, revelando situação diferenciada entre homens e mulheres migrantes no Sudeste, relativamente ao restante do Brasil. Já Marandola Jr. se dedica a uma avaliação crítica a respeito do livro de John Urry, que trata da mobilidade dos indivíduos no mundo contemporâneo.

Quanto ao tema formação de família, Levy trata da escolha do cônjuge, revelando o processo de transformação destas escolhas ao longo do tempo, muito mais influenciadas, nos dias de hoje, final da primeira década do século XXI, por aspectos individuais do que pela estrutura familiar.

Finalmente, Minayo, em seu ponto de vista, aborda a temática mortalidade e reflete sobre os óbitos por causas, com base em duas categorias: a de causas externas e a de violência. Trata-se, portanto, de uma reflexão sobre elementos importantes para a melhoria das condições de vida e saúde no Brasil.

Como vocês podem ver, o conteúdo é heterogêneo e instigante, o que certamente contribuirá para aumentar a difusão da revista e representará um convite especial para que você e seus pares, abepianos ou não, também submetam sua produção científica para veiculação na Rebep.

Boa leitura.

\author{
luri da Costa Leite \\ Carla Jorge Machado \\ Editores
}

